\author{
Muhammad U. Farooq \\ Arshad Majid \\ Joseph J. Pysh \\ Mounzer Y. Kassab
}

\section{Role of intravenous levetiracetam in status migrainosus}

Received: 10 February 2007

Accepted in revised form: 7 March 2007

Published online: 11 May 2007
Migraine pathophysiology remains elusive. A relationship between migraine and epilepsy has been proposed [1] and antiepileptic drugs (AEDs) are being used extensively for migraine prophylaxis and treatment. Newer AEDs with novel mechanisms of action may also help to prevent and treat migraines. The availability of an IV form of an AED allows rapid administration and therefore could be used in the management of status migrainosus (SM). Levetiracetam (LEV) is one of the newer AEDs and has multiple mechanisms of action including favourable interactions with gamma amino butyric acid (GABA) and glycine receptors, antagonism of the activity of negative modulators of GABA, modulation of $\mathrm{N}$-type calcium and glycine-gated currents, and the selective binding to the synaptic vesicle protein $2 \mathrm{~A}[2,3]$. The role of LEV in prophylaxis of refractory migraines and other headache syndromes has been reported [4-7]. The IV form of levetiracetam (IV-LEV) has recently become available. With all the advantages of the newer-generation AEDs, including the minimal side effects and drug interactions, IV-LEV might also be a potential candidate for the treatment of migraine and SM.

We report the case of a 27-year- old woman with a history of migraine with aura and complex partial (CP) epilepsy with occasional secondary generalisation. She had been seizurefree on oral LEV $750 \mathrm{mg}$ twice daily for 2 years. She came to the emergency department (ED) with worsening of her usual migraine headaches for more than $72 \mathrm{~h}$. In the ED, she suffered a 2-min episode of CP seizure with secondary generalisation and was given an infusion of $1000 \mathrm{mg}$ IV-LEV over $15 \mathrm{~min}$. She returned to her clinical baseline and her headache resolved $35 \mathrm{~min}$ after the infusion. She tolerated the infusion well and without side effects. She was observed for $24 \mathrm{~h}$ and maintained on her usual oral LEV without any breakthrough seizures or headaches.

\footnotetext{
M.U. Farooq • A. Majid J.J. Pysh • M.Y. Kassab Department of Neurology and Ophthalmology, Michigan State University, East Lansing, MI, USA
}

M.Y. Kassab (ه) 138 Service Road, A-217 Clinical Center, Michigan State University, East Lansing, MI 48824, USA e-mail: mounzer.kassab@ht.mu.edu Tel.: +1-517-353-8122 Fax: +1-517-432-9414 


\section{References}

1. Niedermeyer E, Vining EP (1993) Migraine-triggered epilepsy.

Clin Electroencephalogr 24:37-43

2. Rigo JM, Hans G, Nguyen L et al (2002) The anti-epileptic drug levetiracetam reverses the inhibition by negative allosteric modulators of neuronal gaba- and glycine-gated currents. Br J Pharmacol 136:659-672

3. Gillard M, Chatelain P, Fuks B (2006) Binding characteristics of levetiracetam to synaptic vesicle protein $2 \mathrm{a}$ (sv2a) in human brain and in cho cells expressing the human recombinant protein. Eur J Pharmacol 536:102-108
4. Brighina F, Palermo A, Aloisio A et al (2006) Levetiracetam in the prophylaxis of migraine with aura: a 6-month open-label study. Clin Neuropharmacol 29:338-342

5. Krusz JC (2001) Levetiracetam as prophylaxis for resistant headaches. Cephalalgia 21:373
6. Gallai V, Alberti A, Rossi C et al (2003) An open label pilot study on the efficacy and tolerability of levetiracetam in the prophylaxis of migraine. J Headache Pain 4:92-96

7. Di Trapani G, Mei D, Vollono C et al (2004) Antiepileptic drugs in the treatment of headache: neuroprotective effect or something else? J Headache Pain 5 [Suppl 2]:S117-S120 